\title{
Glycemic control in non-diabetic critically ill patients
}

\author{
Farnoosh Farrokhi, MD ${ }^{1}$ [Fellow of Endocrinology], Dawn Smiley, MD ${ }^{2}$ [Assistant \\ Professor of Medicine], and Guillermo E. Umpierrez, MD* [Professor of Medicine] \\ Department of Medicine, Division of Endocrinology, Emory University School of Medicine, 49 \\ Jesse Hill Jr Dr. Atlanta, GA 30303, USA
}

\begin{abstract}
Hyperglycemia is a common and costly health care problem in hospitalized patients. In hospital hyperglycemia is defined as any glucose value $>7.8 \mathrm{mmol} / \mathrm{l}(140 \mathrm{mg} / \mathrm{dl})$. Hyperglycemia is present in $40 \%$ of critically ill patients and in up to $80 \%$ of patients after cardiac surgery, with $~ 80 \%$ of ICU patients with hyperglycemia having no history of diabetes prior to admission. The risk of hospital complications relates to the severity of hyperglycemia, with a higher risk observed in patients without a history of diabetes compared to those with known diabetes. Improvement in glycemic control reduces hospital complications and mortality; however, the ideal glycemic target has not been determined. A target glucose level between 7.8 and $10.0 \mathrm{mmol} / \mathrm{l}(140$ and $180 \mathrm{mg} / \mathrm{dl})$ is recommended for the majority of ICU patients. This review aims to present updated recommendations for the inpatient management of hyperglycemia in critically ill patients with and without a history of diabetes.
\end{abstract}

\section{Keywords}

stress hyperglycemia; inpatient hyperglycemia; hospital hyperglycemia; ICU

\section{Prevalence of hyperglycemia in the hospitalized patient}

The prevalence of diabetes around the world is alarmingly high and it is growing. The World Health Organization (WHO) estimated that in 2000 there were 171 million people with diabetes in the world and by 2030, that number is expected to rise to 366 million. ${ }^{1}$ The American Diabetes Association (ADA) estimated that in 2007 there were 23.6 million people in the United States suffering from diabetes, which made up $7.8 \%$ of the population, ${ }^{2}$ and the Centers for Disease Control recently reported that $8.3 \%$ are affected. ${ }^{3}$ Diabetes is the 7th leading cause of death, ${ }^{3,4}$ and is the fourth leading comorbid condition among hospital discharges in the United States. ${ }^{5}$ Adult patients with diabetes are hospitalized substantially more frequently than non-diabetic persons. ${ }^{6}$ Approximately one in four patients admitted to the hospital has a known diagnosis of diabetes, ${ }^{7,8}$ and about $30 \%$ of patients with diabetes require 2 or more hospitalizations in any given year. ${ }^{8}$

The exact prevalence of hospital hyperglycemia is not known but it varies based on study populations and definition utilized in previous reports. Observational studies have reported a prevalence of hyperglycemia ranging from $32 \%$ to $38 \%$ in community hospitals,,${ }^{7,9,10} 41 \%$ of critically ill patients with acute coronary syndromes, ${ }^{11} 44 \%$ of patients with heart

\footnotetext{
(C) 2011 Elsevier Ltd. All rights reserved

"Corresponding author. Tel.: +1 404778 1665; Fax: +1 404778 1661. Farnoosh.farrokhi@emory.edu (F. Farrokhi), dsmiley@emory.edu (D. Smiley), geumpie@emory.edu (G.E. Umpierrez)..

1Tel.: +1 404778 1663; Fax: +1 4047781661 .

2Tel.: +1 404778 1664; Fax: +1 4047781661 .
} 
failure, ${ }^{11}$ and $80 \%$ of patients after cardiac surgery. ${ }^{12,13}$ The occurrence of hyperglycemia is even more evident in critically ill patients where $31 \%$ of the population will have at least one blood glucose reading $11.1 \mathrm{mmol} / \mathrm{l}(200 \mathrm{mg} / \mathrm{dl})$ and nearly $100 \%$ will have a blood glucose $>6.1 \mathrm{mmol} / \mathrm{l}(110 \mathrm{mg} / \mathrm{dl})$ during intensive care unit (ICU). ${ }^{7,10,14}$ These patients may have previously undiagnosed diabetes, receiving a diagnosis for the first time and others might manifest "stress hyperglycemia" during an acute illness that resolves by the time of discharge. ${ }^{15}$ This paper will review the guidelines for diagnosing stress

hyperglycemia, mechanisms underlying hyperglycemia, the benefits of glycemic control, and current management recommendations for inpatient hyperglycemia.

\section{Diagnosis of stress hyperglycemia in hospital setting}

The American Diabetes Association and American Association of Clinical Endocrinologists consensus on inpatient hyperglycemia defined stress hyperglycemia or hospital-related hyperglycemia as any blood glucose concentration $>7.8 \mathrm{mmol} / \mathrm{l}(140 \mathrm{mg} / \mathrm{dl})$ without evidence of previous diabetes. Although stress hyperglycemia typically resolves as the acute illness or surgical stress abates, it is important to identify and track patients as $60 \%$ of patients admitted with new hyperglycemia had confirmed diabetes at 1 year. ${ }^{16}$ Wexler et al showed that nearly one in five adult patients with "stress" hyperglycemia have probable unrecognized diabetes as identified by an admission HbAlc $>6.1 \%$ which speaks to the fact that nearly one-third of patients with diabetes are unaware of their diagnosis. ${ }^{3}$ Crosssectional studies of patients with stress hyperglycemia revealed that $\sim 30 \%-60 \%$ of patients with stress hyperglycemia have impaired carbohydrate intolerance or diabetes during follow-up. ${ }^{16}$

Until recently, clinical guidelines recommended that all patients with stress hyperglycemia should be tested with an oral glucose tolerance test (OGTT) shortly after discharge to assess carbohydrate tolerance. ${ }^{17}$ More recently, the use of $\mathrm{HbA} 1 \mathrm{c}$ has been recommended over OGTT as the preferred diagnostic testing in hospitalized patients with hyperglycemia. ${ }^{18}$ Measurement of an HbAlc during periods of hospitalization provides the opportunity to differentiate patients with stress hyperglycemia from those with diabetes who were previously undiagnosed, as well as to identify patients with known diabetes who would benefit from intensification of their glycemic management regimen. ${ }^{19,20}$ However, it is important to emphasize that an HbA1c cutoff of $>6.5 \%$ identifies one-third fewer cases of undiagnosed diabetes than a high fasting glucose value. ${ }^{21}$ Several epidemiologic studies have reported a low sensitivity (44\%-66\%) but a high specificity (76\%-99\%) for HbA1c > $6.5 \%$ in an outpatient population. ${ }^{22,23}$ In addition HbA1c testing has significant limitation in the presence of hemoglobinopathies (i.e. sickle cell, thalassemia) recent transfusion, severe hepatic or liver disease, high-dose salicylates, and iron deficiency anemia. ${ }^{24,25}$ Finally, it is recommended that when an $\mathrm{HbA1c}$ is used for establishing a diagnosis of diabetes, it should be performed using a method certified by the National Glycohemoglobin Standardization Program ${ }^{21,25}$ as point of care HbA1c testing is not sufficiently accurate at this time to be used for diagnosis of diabetes.

\section{Mechanisms of stress hyperglycemia in hospitalized patients}

Hyperglycemia is a frequent manifestation of critical and surgical illness, resulting from the acute metabolic and hormonal changes associated with the response to injury and stress. ${ }^{26,27}$ Acute illness, surgery, and trauma raise levels of counterregulatory hormones such as glucagon, epinephrine, cortisol, and growth hormone. The counterregulatory response results in a number of alterations in carbohydrate metabolism, including insulin resistance, increased hepatic glucose production, impaired peripheral glucose utilization, and relative insulin deficiency. Epinephrine stimulates glucagon secretion and inhibits insulin release by 
pancreatic $\beta$-cells. ${ }^{28}$ High cortisol levels increase hepatic glucose production, and stimulate protein catabolism and increased circulating amino acids concentration, providing precursors for gluconeogenesis. ${ }^{29,30}$ In addition, acute stress increases pro-inflammatory cytokines such as tumor necrosis factor-alpha (TNF-a), interleukin (IL)-6, and IL-1, 26,31-33 which increase insulin resistance by interfering with insulin signaling. TNF- $a$ activates cJun NH2-terminal kinase (JNK), a signaling protein molecule that phosphorylates insulin receptor substrate-1 (IRS-1) and prevents insulin-mediated activation of phosphatidylinositol 3-kinase (PI 3-kinase) involved in tissue glucose uptake. Downstream effect process decreases insulin stimulation of glucose uptake and causes hyperglycemia. ${ }^{34,35}$ Thus stress adversely affects multiple biological processes resulting in diminished insulin action and if the pancreas is unable to compensate by increasing insulin production, the end result is the appearance of hyperglycemia. Furthermore, in the presence of hyperglycemia, the pancreatic $\beta$-cells develop desensitization that results in further blunting of insulin secretion and increasing serum glucose levels. ${ }^{36}$

Counterregulatory hormones in the setting of stress lead to enhanced lipolysis and increasing fatty acids (FFAs) concentration. ${ }^{37,38}$ In patients with ischemic cardiovascular events, high FFA levels can aggravate ischemia/reperfusion damage by limiting the ability of cardiac muscle to uptake glucose for anaerobic metabolism. ${ }^{39,40}$ FFAs, normally the substrate of choice for healthy myocardium, are toxic to an ischemic myocardium ${ }^{39,40}$ leading to cardiac arrhythmias, sympathetic overactivity, increased blood pressure, oxidative stress and endothelial dysfunction. ${ }^{41-43}$ Increased FFA levels also produce dose-dependent insulin resistance in peripheral tissues ${ }^{44}$ andincrease hepatic glucose output in both diabetic and non-diabetic individuals. ${ }^{27,45}$ Hyperglycemia state caused by these mechanisms often times is worsened by exogenous use of glucose in form of nutritional supports or intravenous dextrose in critical care settings. ${ }^{13}$

The development of hyperglycemia leads to generation of reaction oxygen species (ROS), Lipid peroxidation, elevated cardiovascular inflammatory markers. (Fig. 1) Acute hyperglycemia may induce cardiac myocyte death through apoptosis or by exaggerating ischemia-reperfusion cellular injury. ${ }^{46,47}$ It also has deleterious effect on endothelial function by suppressing formation of nitric oxide (NO) and impairing endotheliumdependent flow mediated dilation. ${ }^{48}$ In addition, hyperglycemia-induced abnormalities in hemostasis including increased platelet activation, adhesion and aggregation, ${ }^{49}$ reduced plasma fibrinolytic activity and increased plasminogen activator inhibitor-1 (PAI-1) activity. ${ }^{50}$ In vitro and in vivo studies have also shown that hyperglycemia also impairs immune system function by reducing phagocytic activity of macrophages, impairing chemotaxis of polymorphonuclear neutrophils (PMNs), increasing expression of adhesion molecules and free radical production in immune cells which will ultimately increase the risk of infection and multiple in hospital complications ${ }^{51,52}$ (Fig. 1).

\section{Consequences of stress hyperglycemia in hospitalized patients}

Extensive observational and prospective randomized trials in patients with critical illness indicate a strong association between hyperglycemia and poor clinical outcome, such as mortality, morbidity, length of stay, infections and overall complications. ${ }^{7,53}$ The impact of hyperglycemia on outcome may be related to the presence of pre-existing diabetes, the intensity of the hyperglycemic response, the diagnosis, and the risk for infection. A retrospective study in a community teaching hospital reported that subjects with newly diagnosed or stress hyperglycemia had increased hospital mortality and longer stay in the hospital, and were more likely to require transitional or nursing home care after discharge when compared to patients with known diabetes and normoglycemia. ${ }^{7}$ In a different study, patients with acute myocardial infarction and stroke had higher rate of mortality and 
cardiovascular complications than those with history of diabetes. ${ }^{7}$ It is estimated that for each $1 \mathrm{mmol} / \mathrm{L}$ ( $18 \mathrm{mg} / \mathrm{dL}$ ) rise in admission fasting plasma glucose is associated with 33\% increase in mortality ${ }^{54}$ In studies of patients undergoing coronary artery bypass surgery (CABG), irrespective of pre-existing diabetes, it was reported that those with elevated hospital BG values of $>200 \mathrm{mg} / \mathrm{dL}$ compared to lower values had higher mortality, more wound infections and longer hospital stays. ${ }^{53,55,56}$

A recent retrospective analysis of 259040 patients admitted to a University-affiliated Veterans Affairs Medical Center (VAMC) demonstrated a significant association between hyperglycemia and adjusted mortality in unstable angina, acute myocardial infarction, congestive heart failure, arrhythmia, ischemic and hemorrhagic stroke, gastrointestinal bleeding, acute renal failure, pneumonia, pulmonary embolism, and sepsis. ${ }^{57}$ The mortality risk was significantly greater at each quartile range of blood glucose for patients without a history of diabetes in this large VAMC database.

\section{Glycemic control in critical care setting}

Early intervention of randomized controlled studies intensified glucose control with administration of Intravenous insulin both in medical and surgical patients reported a reduction in multi-organ failure, systemic infection as well as short and long-term mortality. ${ }^{13,56,58-60}$ It seems that glucose control rather than administration of exogenous insulin is the dominant factor in improving mortality. ${ }^{61}$

In a non-randomized prospective study on 2,467 patients undergoing open-heart surgery, Furnary et al ${ }^{62}$ showed that continuous insulin infusion to achieve perioperative BG target level of $8.3-11.1 \mathrm{mmol} / \mathrm{l}(150-200 \mathrm{mg} / \mathrm{dl})$ as compared to levels $>11.1 \mathrm{mmol} / \mathrm{l}(\mathrm{BG}>200$ $\mathrm{mg} / \mathrm{dl}$ ) reduced the risk of death and deep sternal wound infection by more than half. The authors reported additional risk reduction by lowering the glycemic target to $6.9-9.7 \mathrm{mmol} / \mathrm{l}$ $(125-175 \mathrm{mg} / \mathrm{dl})$ and later on to $5.5-8.3 \mathrm{mmol} / 1(100-150 \mathrm{mg} / \mathrm{dl}){ }^{63}$

The Leuven study ${ }^{13}$ was the first randomized control trial that set the stage for aggressive glycemic control in critical care setting a decade ago. This study randomized 1548 patients admitted to surgical ICU ( 60\% cardiac case, $86 \%$ non-diabetic with hyperglycemia) were randomized to either receive intensive insulin therapy to maintain target BG level of 4.4-6.1 $\mathrm{mmol} / \mathrm{l}(80-110 \mathrm{mg} / \mathrm{dl})$ or conventional treatment for target between 10 and $11.1 \mathrm{mmol} / \mathrm{l}$ $(180-200 \mathrm{mg} / \mathrm{dl})$. Compared to the conventional treatment arm with an average daily BG of $8.5 \mathrm{mmol} / 1(153 \mathrm{mg} / \mathrm{dl}$ ), patients in the intensive insulin treatment (average BG level 5.7 $\mathrm{mmol} / \mathrm{l}[103 \mathrm{mg} / \mathrm{dl}]$ ) had significantly less bacteremia, acute renal failure number of red cell transfusions, critical illness associated polyneuropathy and prolonged mechanical ventilation. The ICU mortality was also reduced by half in the intensive insulin treatment arm and the benefit was even greater for those who remained in the intensive care unit for more than five days. In a post-hoc analysis of this study, it was found that those with a previous diagnosis of diabetes were at lower risk of mortality than patients without diabetes or with newly-diagnosed diabetes (OR 0.356, 95\% CI: $0.158-0.803, p=0.01) .{ }^{56}$ Severe hypoglycemia $(\mathrm{BG}<2.2 \mathrm{mmol} / \mathrm{l}, 40 \mathrm{mg} / \mathrm{dl})$ occurred in $5 \%$ of intensive insulin treatment vs. $7 \%$ in conventional treatment.

Counterpart to the above study, Van den Berghe et al reported a randomized controlled trial in medical ICU patients ( $83 \%$ non-diabetics with hyperglcemia) ${ }^{60}$ using the same treatment arms and glucose targets. When evaluated in an intention-to-treat analysis, there were no differences in-hospital mortality ( $37.3 \%$ vs. $40 \%, P=0.33$ ) between the intensive group (mean BG achieved $111 \mathrm{mg} / \mathrm{dl}$ ) and conventional group (mean BG achieved $153 \mathrm{mg} / \mathrm{dL}$ ). Further analysis of the data for those treated in the ICU for longer than 3 days revealed a reduction in ICU mortality $(31.3 \%$ vs. $38.1 \%, p=0.05)$ and total hospital mortality ( $43 \%$ vs. 
$52 \%, p=0.009)$. The benefit of mortality was only observed among non-diabetic patients and not in patients with pre-existing diabetes. Risk of hypoglycemia (BG $<2.2 \mathrm{mmol} / \mathrm{l}, 40$ $\mathrm{mg} / \mathrm{dl}$ ) was also increased among those with intensive insulin treatment compared to conventional arm and it was found to be an independent risk factor for death. ${ }^{56}$ Other studies also showed benefit for tight blood glucose control in critical care setting with 30-60\% reduction in mortality (Table 1). ${ }^{62,64}$

Despite these positive results, multiple recent studies have shown increased mortality risk with intensive glycemic control (Table 2) ${ }^{65-69}$ The Glucontrol trial, a seven-country, multicenter trial, randomized patients in medical and surgical ICUs to tight glycemic control (BG 4.4-6.1 mmol/1; 80-110 mg/dl) versus conventional glycemic control (BG 7.8-10 $\mathrm{mmol} / \mathrm{l} ; 140-180 \mathrm{mg} / \mathrm{dl}$ ). The study was discontinued prematurely due to protocol violations and safety concerns about hypoglycemia in the intensive arm without difference in mortality between the two groups. ${ }^{70}$ Similarly, the Efficacy of Volume Substitution and Insulin Therapy in Sepsis (VISEP) study ${ }^{65}$ in ICU patients with sepsis randomized to receive intensive insulin treatment to maintain BG levels 4.4-6.1 (80-110 mg/dL) and 10-11.1 $\mathrm{mmol} / \mathrm{L}(180-200 \mathrm{mg} / \mathrm{dL})$ showed no difference at 28 day or 90 day mortality between groups, but intensive treatment resulted in significantly greater number of severe hypoglycemic events (12.1 vs. $2.1 \%$ ). The NICE-SUGAR trial, ${ }^{67}$ a large trial with more than 6000 medical and surgical ICU subjects randomized patients to receive either intensive insulin treatment (target BG: $4.5-6 \mathrm{mmol} / \mathrm{l} ; 81-108 \mathrm{mg} / \mathrm{dl}$ ) or conventional control (target $\mathrm{BG}<10 \mathrm{mmol} / \mathrm{l} ;<180 \mathrm{mg} / \mathrm{dl}$ ). This study reported no significant difference in hospital mortality or length of stay between groups, and compared with the control arm, the intensive treatment group had an absolute increase in 90 -day mortality $(27.5 \%$ vs. $24.9 \%, p=0.02)$ and an increased incidence of hypoglycemia ( $6.8 \%$ vs. $0.5 \%, p<0.001)$.

The results of recent trials have also shown that it is difficult to achieve and maintain tight glycemic control (BG 4.5-6 mmol/l, 80-110 $\mathrm{mg} / \mathrm{dl}$ ) without increasing the risk for severe hypoglycemia $(\mathrm{BG}<2.2 \mathrm{mmol} / \mathrm{l}, 40 \mathrm{mg} / \mathrm{dl}) .{ }^{65-68}$ The incidence of severe hypoglycemia among the different trials ranged between $5 \%$ and $28 \%$ depending on the intensity of glycemic control (Table 2). Studies have suggested that there is an increased risk of in hospital complications and mortality in patients who experienced severe hypoglycemia. ${ }^{71,72}$ In a retrospective cohort study on patients with acute myocardial infarction, those with hypoglycemia had higher mortality compared to patients without hypoglycemic event $(12.7 \%$ vs $9.6 \%, P=0.03)$, and the relationship between hypoglycemia and mortality was similar in patients with and without known history of diabetes. ${ }^{73}$ Despite these observations, the direct causal effect of iatrogenic hypoglycemia on adverse outcome is still debatable. A recent study assessing the impact of iatrogenic vs. spontaneous hypoglycemia in critical illness, Kosiborod et $\mathrm{al}^{73}$ reported that spontaneous hypoglycemia is associated with higher in hospital mortality and that insulin-induced hypoglycemia was not associated with increased risk of death compare to subjects without hypoglycemia. This raised up the possibility that hypoglycemia is a marker of vulnerability rather than a direct cause of adverse outcomes. ${ }^{71,73}$

\section{Blood glucose measurement}

Frequent blood glucose monitoring is essential for optimally managing hyperglycemia in patients admitted to critical care units. Patients treated with continuous IV insulin generally require hourly testing until blood glucose levels are stable, followed by testing every $2 \mathrm{~h}$. Patients with or without a history of diabetes receiving enteral or parenteral nutritional support should undergo glucose testing every $4-6 \mathrm{~h}$. Blood glucose testing can be discontinued in patients without a prior history of diabetes if glucose values are $<7.8 \mathrm{mmol} /$ $\mathrm{L}(140 \mathrm{mg} / \mathrm{dL})$ without insulin therapy for $24-48 \mathrm{~h}$ following achievement of desired caloric intake. For patients who are able to eat, glucose measurement is usually performed four 
times a day: before meals and at bedtime for patients who are eating. Pre-meal glucose testing should be obtained as close to the time of the meal tray delivery as possible, and no longer than $1 \mathrm{~h}$ before meals. ${ }^{55}$ More frequent glucose monitoring is indicated after a medication change that could alter glycemic control, e.g., corticosteroid use, abrupt discontinuation of enteral or parenteral nutrition, or in patients with frequent episodes of hypoglycemia.

There are different methods for obtaining blood glucose levels in ICU. Measuring arterial glucose level using blood gas analyzers is the most accurate method. ${ }^{74}$ Laboratory analysis of plasma glucose of venous sampling is accurate but this approach is slow for use in ICU. ${ }^{75}$ Bedside capillary point of care (POC) testing is the preferred method for guiding ongoing glycemic management in the hospital; however this method may be inaccurate by up to $20 \%$ compared to the plasma glucose particularly in patients with lower glucose levels, hypotension or anemia. ${ }^{76}$ Recent studies suggest that continuous BG monitoring devices may be helpful in reducing incidences of severe hypoglycemia in acute care. ${ }^{77,78}$ More studies, however, are needed to determine the accuracy and reliability of continuous BG monitoring devices in hospitalized patients. Although promising, continuous BG monitoring has not been adequately tested in acute care and therefore cannot be recommended for hospitalized patients at this time.

\section{Glycemic targets in critical care settings}

Based on the results of recent trials, the American Association of Clinical Endocrinologist and American Diabetes Association ${ }^{79}$ task force on inpatient glycemic control recommended targeting a BG level between 7.8 and $10.0 \mathrm{mmol} / \mathrm{l}(140$ and $180 \mathrm{mg} / \mathrm{dl})$ for the majority of ICU patients and a lower glucose targets between 6.1 and $7.8 \mathrm{mmol} / \mathrm{l}(110$ and $140 \mathrm{mg} / \mathrm{dl}$ ) in selected ICU patients (i.e. centers with extensive experience and appropriate nursing support, cardiac surgical patients, patients with stable glycemic control without hypoglycemia). Glucose targets $>10 \mathrm{mmol} / \mathrm{l}(>180 \mathrm{mg} / \mathrm{dl})$ or $<6.1 \mathrm{mmol} / \mathrm{l}(<110$ $\mathrm{mg} / \mathrm{dl})$ are not recommended in ICU patients. ${ }^{74,79}$

\section{Treatment of hyperglycemia in critically ill patients}

The use of insulin is the preferred therapeutic agent for blood glucose control in the hospital setting. Intravenously administered insulin is most beneficial to critically ill patients with or without a history of diabetes. ${ }^{80}$ Because of the very short half-life of circulating insulin, IV delivery allows rapid dosing adjustments to address alterations in patients' status. Insulin infusion is ideally administered via validated written or computerized protocols that allow for predefined adjustments to the insulin infusion rate according to glycemic fluctuations and insulin dose. ${ }^{74}$

The administration of IV insulin is more predictable and effective in controlling hyperglycemia than subcutaneous (SQ) insulin therapy; however, it is labor intensive and requires admission to the ICU in majority of medical centers. Once patient's condition stabilizes (e.g., consistent feeding administration, lack of significant edema, no vasopressors) IV insulin infusion can be transitioned to SQ. Several models have been proposed for transition from insulin infusion to SQ insulin therapy ${ }^{81-84}$ In general, the initial dose and distribution of SQ insulin at the time of transition can be determined by extrapolating the IV insulin requirement over the preceding $6-8 \mathrm{~h}$ to a $24-\mathrm{h}$ period. Administering $80 \%$ of the total daily calculated dose as basal insulin has been demonstrated to be both safe and efficacious in surgical patients. ${ }^{47,83}$ It is important that consideration be given to a patient's nutritional status and medications, with continuation of glucose monitoring to guide ongoing adjustments in the insulin dose, as changes in insulin sensitivity can occur during acute illness. 
During the transition to SQ insulin, abasal and bolus insulin regimen has been demonstrated to be effective and safe in medical and surgical patients. ${ }^{85}$ The basal bolus models include a three component approach to insulin replacement: basal insulin, nutritional insulin, and correction insulin. ${ }^{86,87}$ Basal insulin is provided as an injection of basal insulin analogs given every $24 \mathrm{~h}$ (glargine, detemir) or intermediate-acting human insulin given every 8-12 $\mathrm{h}$ (e.g., NPH). Basal insulin analogs have duration of action of approximately $24 \mathrm{~h}$ with no pronounced peak, providing a more physiologic basal insulin supply than NPH insulin. Prandial insulin can be given with regular human insulin or with rapid-acting insulin analogs (lispro, aspart and glulisine). Regular insulin has a slow onset of action and must be injected 30-45 min before a meal. In the hospital setting, timing regular insulin with meals is inconvenient and can produce hypoglycemia if a meal is delayed or skipped. Rapid-acting insulin analogs closely mimic the normal postprandial insulin response and have a more rapid onset (5-15 min), peak action (45-60 $\mathrm{min}$ ), and a shorter duration of action than regular human insulin.

The effectiveness and safety of premixed insulin preparations have not been tested in hospitalized patients. These formulations do not reliably mimic patterns of physiologic insulin release and may cause between-meal and nocturnal hypoglycemia. ${ }^{88}$ In addition, the use of oral and other non-insulin therapies are not recommended as they are relative contraindicated in many clinical situations (sepsis, NPO status, IV contrast dye, pancreatic disorders, etc.). Sulfonylureas are long-acting insulin secretagogues that can cause severe and prolonged hypoglycemia, particularly in the elderly or those with chronic kidney disease. ${ }^{88}$ Metformin must be discontinued in patients with decompensated congestive heart failure, renal insufficiency, hypoperfusion, or chronic pulmonary disease ${ }^{88}$ and in patients who are at risk of developing renal failure and lactic acidosis such as may occur with the administration of IV contrast dye or surgery. Thiazolidinediones can take several weeks for the full hypoglycemic effect and are contraindicated in patients with congestive heart failure, hemodynamic instability, or evidence of hepatic dysfunction.

\section{Recommendations at hospital discharge}

Measurement of $\mathrm{HbA} 1 \mathrm{C}$ concentration during the hospital stay can assist in tailoring the glycemic management at discharge. Patients with $\mathrm{HbA} 1 \mathrm{C}<6.5 \%$ can usually be discharged on no antidiabetic medications. Patients with elevated $\mathrm{HbA1C}$ can be treated with insulin, oral antidiabetic agents or combination therapy. For patients discharged home on insulin therapy as a new medication, it is important that written information be provided for the method and timing of administration of prescribed doses and recognition and treatment of hypoglycemia ${ }^{89}$. Insulin regimens are often complex, usually entailing the administration of two different insulin preparations that may require adjustments according to home glucose readings. Because hospital discharge can be stressful to patients and their family, orally communicated instructions alone are often inadequate. To address this problem, several institutions have established formalized discharge instructions for patients with diabetes as a way of improving the clarity of instructions for insulin therapy and glucose monitoring. ${ }^{90,91}$

\section{Summary}

Hyperglycemia is a common finding in critically ill patients with and without diabetes. Observational and randomized controlled studies indicate that improvement in glycemic control results in lower rates of hospital complications and mortality. Intravenous insulin infusion is the preferred regimen for critically ill patients with or without a history of diabetes. During transition from intravenous to subcutaneous insulin therapy, the use of basal, nutritional and correction components rather than the sole use of sliding scale insulin regimen is the preferred method for achieving and maintaining glucose control. 
Implementing a standardized subcutaneous insulin order set promoting the use of scheduled basal and nutritional insulin therapy is a key intervention in the inpatient management of diabetes. Several guidelines and position statements offer medical institutions evidencebased guidelines for the management of inpatient hyperglycemia in both the ICU and nonICU settings; however, more research is needed to further delineate the patient populations that would benefit most from tighter glycemic control and which insulin regimens are the safest and most effective.

\section{Acknowledgments}

Dr. Umpierrez is supported by research grants from the American Diabetes Association (7-07-CR-56), NIH/NCRR Clinical Translational Science Award (M01 RR-00039) and has received research funding from Sanofi-Aventis, Merck and Glaxo Pharmaceuticals. Dr. Smiley receives research support from the National Institute of Health (K08 DK0830361).

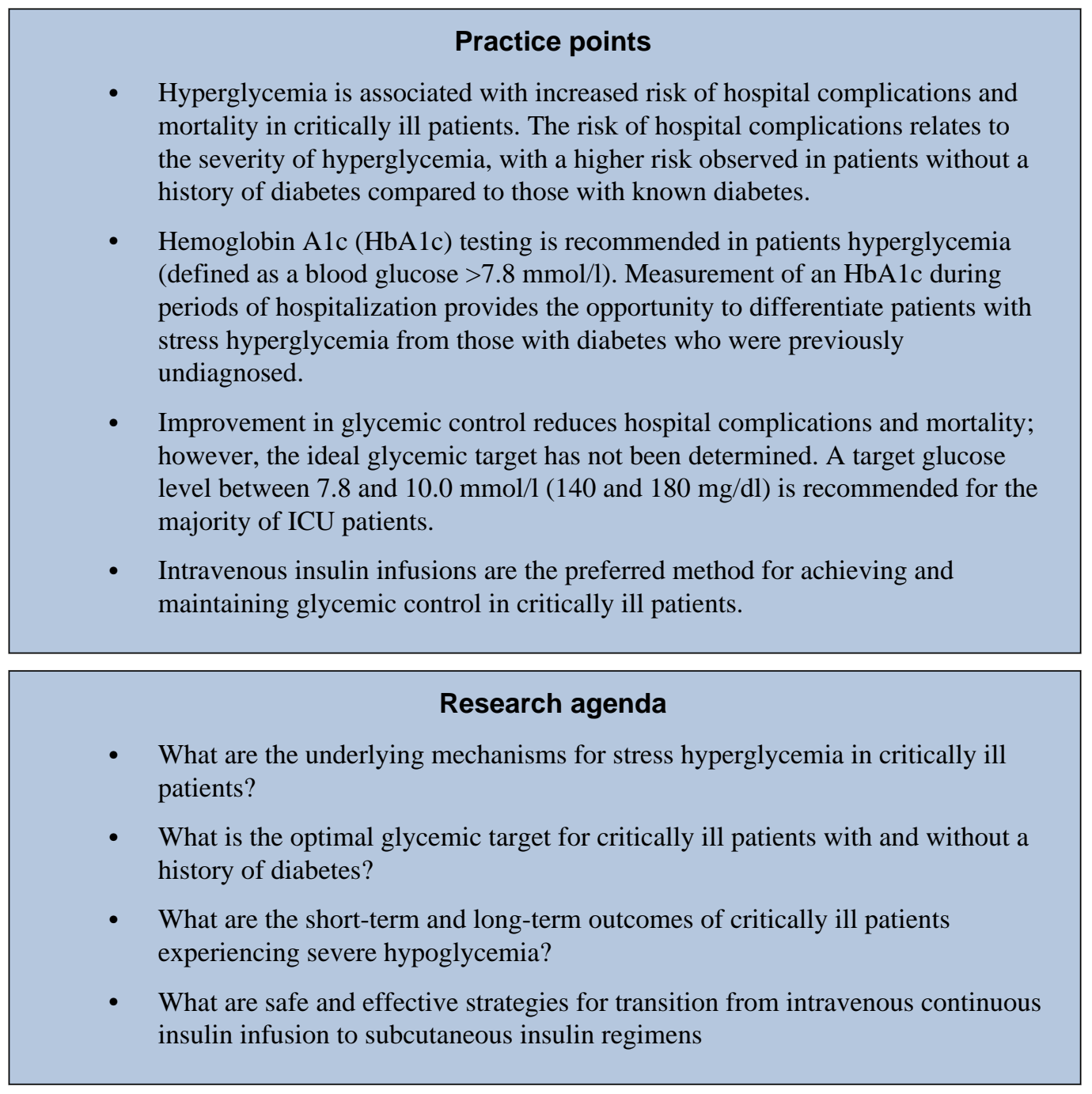

\section{References}

1. Organization WH. Prevalence of diabetes Worldwide. 2010. vol [World Health Organization website] 
2. Association AD. Diabetes Statistics. Diabetes Basics. 2010. vol [American Diabetes Association website]

3. U.S. Department of Health and Human Services CfDCaP. National estimates and general information on diabetes and prediabetes in the United States. National diabetes fact sheet; 2011.

4. Xu J, Kochanek KD, Murphy SL, et al. Deaths: Final data for 2007. National vital statistics reports web release. 2010; 58(19)

5. Elixhauser, AYK.; Steiner, C.; Bierman, AS. Hospitalization in the United States, 1997. Agency for Healthcare Research and Quality; Rockville, MD: 2000. HCUP Fact Book No. 1; AHRQ Publication No. 00-0031.

6. Harris MI. Medical care for patients with diabetes. Epidemiologic aspects. Annals of Internal Medicine. 1996; 124(1 Pt 2):117-122. [PubMed: 8554202]

*7. Umpierrez GE, Isaacs SD, Bazargan N, et al. Hyperglycemia: an independent marker of in-hospital mortality in patients with undiagnosed diabetes. Journal of Clinical Endocrinology and Metabolism. 2002; 87(3):978-982. [PubMed: 11889147]

8. Jiang HJ, Stryer D, Friedman B, et al. Multiple hospitalizations for patients with diabetes. Diabetes Care. 2003; 26(5):1421-1426. [PubMed: 12716799]

9. Cook CB, Kongable GL, Potter DJ, et al. Inpatient glucose control: a glycemic survey of 126 U.S. hospitals. Journal of Hospital Medicine. 2009; 4(9):E7-E14. [PubMed: 20013863]

10. Levetan CS, Passaro M, Jablonski K, et al. Unrecognized diabetes among hospitalized patients. Diabetes Care. 1998; 21(2):246-249. [PubMed: 9539990]

11. Kosiborod M, Inzucchi SE, Spertus JA, et al. Elevated admission glucose and mortality in elderly patients hospitalized with heart failure. Circulation. 2009; 119(14):1899-1907. [PubMed: 19332465]

12. Schmeltz LR, DeSantis AJ, Thiyagarajan V, et al. Reduction of surgical mortality and morbidity in diabetic patients undergoing cardiac surgery with a combined intravenous and subcutaneous insulin glucose management strategy. Diabetes Care. 2007; 30(4):823-828. [PubMed: 17229943]

*13. van den Berghe G, Wouters P, Weekers F, et al. Intensive insulin therapy in the critically ill patients. New England Journal of Medicine. 2001; 345(19):1359-1367. [PubMed: 11794168]

*14. Krinsley JS. Association between hyperglycemia and increased hospital mortality in a heterogeneous population of critically ill patients. Mayo Clinic Proceedings. 2003; 78(12):14711478. [PubMed: 14661676]

15. Dungan KM, Braithwaite SS, Preiser JC. Stress hyperglycaemia. Lancet. 2009; 373(9677):17981807. [PubMed: 19465235]

16. Greci LS, Kailasam M, Malkani S, et al. Utility of $\mathrm{HbA}(1 \mathrm{c})$ levels for diabetes case finding in hospitalized patients with hyperglycemia. Diabetes Care. 2003; 26(4):1064-1068. [PubMed: 12663574]

17. Garber AJ, Moghissi ES, Bransome ED, et al. American College of Endocrinology position statement on inpatient diabetes and metabolic control. Endocrine Practice. 2004; 10(Suppl. 2):4-9. [PubMed: 15251633]

18. Sonksen PH. Home monitoring of blood glucose by diabetic patients. Acta Endocrinologica. Supplementum. (Copenh). 1980; 238:145-155.

19. Mazurek JA, Hailpern SM, Goring T, et al. Prevalence of hemoglobin A1c greater than $6.5 \%$ and $7.0 \%$ among hospitalized patients without known diagnosis of diabetes at an Urban Inner City hospital. Journal of Clinical Endocrinology and Metabolism. 2010; 95(3):1344-1348. [PubMed: 20080838]

20. Baldwin D, Villanueva G, McNutt R, et al. Eliminating Inpatient Sliding-Scale Insulin: a reeducation project with medical house staff. Diabetes Care. 2005; 28(5):1008-1011. [PubMed: 15855558]

21. Association AD. Standards of medical care in diabetes. Diabetes Care. 2010; 33(Suppl. 1):S11S61. [PubMed: 20042772]

22. Buell C, Kermah D, Davidson MB. Utility of A1C for diabetes screening in the 19992004 NHANES population. Diabetes Care. 2007; 30(9):2233-2235. [PubMed: 17563338]

23. Kramer CK, Araneta MR. Barrett-Connor E. A1C and diabetes diagnosis: the Rancho Bernardo study. Diabetes Care. 33(1):101-103. [PubMed: 19837792] 
24. Saudek CD, Derr RL, Kalyani RR. Assessing glycemia in diabetes using self-monitoring blood glucose and hemoglobin A1c. Jama. 2006; 295(14):1688-1697. [PubMed: 16609091]

25. International Expert Committee report on the role of the A1C assay in the diagnosis of diabetes. Diabetes Care. 2009; 32(7):1327-1334. [PubMed: 19502545]

26. Umpierrez GE, A.E.K. ICU care for patients with diabetes. Current Opinion in Endocrinology and Diabetes. 2004; 11:75-81.

27. McCowen KC, Malhotra A, Bistrian BR. Stress-induced hyperglycemia. Crit Care Clinics. 2001; 17(1):107-124.

28. Scherpereel PA, Tavernier B. Perioperative care of diabetic patients. Eur Journal of Anaesthesiology. 2001; 18(5):277-294.

29. Chan TM. The permissive effects of glucocorticoid on hepatic gluconeogenesis. Glucagon stimulation of glucose-suppressed gluconeogenesis and inhibition of 6-phosphofructo-1-kinase in hepatocytes from fasted rats. The Journal of Biological Chemistry. 1984. 259(12):7426-7432. [PubMed: 6234302]

30. McMahon M, Gerich J, Rizza R. Effects of glucocorticoids on carbohydrate metabolism. Diabetes Metabolism Reviews. 1988; 4(1):17-30. [PubMed: 3278872]

31. Esposito K, Nappo F, Marfella R, et al. Inflammatory cytokine concentrations are acutely increased by hyperglycemia in humans: role of oxidative stress. Circulation. 2002; 106(16):20672072. [PubMed: 12379575]

32. Stentz FB, Umpierrez GE, Cuervo R, et al. Proinflammatory cytokines, markers of cardiovascular risks, oxidative stress, and lipid peroxidation in patients with hyperglycemic crises. Diabetes. 2004; 53(8):2079-2086. [PubMed: 15277389]

33. Lang CH, Dobrescu C, Bagby GJ. Tumor necrosis factor impairs insulin action on peripheral glucose disposal and hepatic glucose output. Endocrinology. 1992; 130(1):43-52. [PubMed: 1727716]

34. Fan J, Li YH, Wojnar MM, et al. Endotoxin-induced alterations in insulin-stimulated phosphorylation of insulin receptor, IRS-1, and MAP kinase in skeletal muscle. Shock. 1996; 6(3): 164-170. [PubMed: 8885080]

35. del Aguila LF, Claffey KP, Kirwan JP. TNF-alpha impairs insulin signaling and insulin stimulation of glucose uptake in C2C12 muscle cells. American Journal of Physiology. 1999; 276(5 Pt 1):E849-E855. [PubMed: 10329978]

36. Robertson RP. Islet transplantation as a treatment for diabetes - a work in progress. The New England Journal of Medicine. 2004; 350(7):694-705. [PubMed: 14960745]

37. Clarke RS, Bali IM, Issac M, et al. Plasma cortisol and blood sugar following minor surgery under intravenous anaesthetics. Anaesthesia. 1974; 29(5):545-550. [PubMed: 4433013]

38. Press M. Growth hormone and metabolism. Diabetes Metabolism Reviews. 1988; 4(4):391-414. [PubMed: 3292176]

39. Oswald GA, Smith CC, Betteridge DJ, et al. Determinants and importance of stress hyperglycaemia in non-diabetic patients with myocardial infarction. British Medical Journal (Clinical Research Ed.). 1986; 293(6552):917-922. [PubMed: 3094714]

40. Norhammar AM, Ryden L, Malmberg K. Admission plasma glucose. Independent risk factor for long-term prognosis after myocardial infarction even in nondiabetic patients. Diabetes Care. 1999; 22(11):1827-1831. [PubMed: 10546015]

41. Trence DL, Kelly JL, Hirsch IB. The rationale and management of hyperglycemia for in-patients with cardiovascular disease: time for change. The Journal of Clinical Endocrinology and Metabolism. 2003; 88(6):2430-2437. [PubMed: 12788838]

42. Steinberg HO, Tarshoby M, Monestel R, et al. Elevated circulating free fatty acid levels impair endothelium-dependent vasodilation. The Journal of Clinical Investigation. 1997; 100(5):12301239. [PubMed: 9276741]

43. Oliver MF, Opie LH. Effects of glucose and fatty acids on myocardial ischaemia and arrhythmias. Lancet. 1994; 343(8890):155-158. [PubMed: 7904009]

44. Roden M, Price TB, Perseghin G, et al. Mechanism of free fatty acid-induced insulin resistance in humans. The Journal of Clinical Investigation. 1996; 97(12):2859-2865. [PubMed: 8675698] 
45. Robinson LE, van Soeren MH. Insulin resistance and hyperglycemia in critical illness: role of insulin in glycemic control. AACN Clinical Issues. 2004; 15(1):45-62. [PubMed: 14767364]

46. Ceriello A, Quagliaro L, D'Amico M, et al. Acute hyperglycemia induces nitrotyrosine formation and apoptosis in perfused heart from rat. Diabetes. 2002; 51(4):1076-1082. [PubMed: 11916928]

47. Clement S, SS Braithwaite, Magee MF, et al. Management of diabetes and hyperglycemia in hospitals. Diabetes Care. 2004; 27(2):553-597. [PubMed: 14747243]

48. Title LM, Cummings PM, Giddens K, et al. Oral glucose loading acutely attenuates endotheliumdependent vasodilation in healthy adults without diabetes: an effect prevented by vitamins $\mathrm{C}$ and E. Journal of the American College of Cardiology. 2000; 36(7):2185-2191. [PubMed: 11127459]

49. Gresele P, Guglielmini G, De Angelis M, et al. Acute, short-term hyperglycemia enhances shear stress-induced platelet activation in patients with type II diabetes mellitus. Journal of the American College of Cardiology. 2003; 41(6):1013-1020. [PubMed: 12651051]

50. Pandolfi A, Giaccari A, Cilli C, et al. Acute hyperglycemia and acute hyperinsulinemia decrease plasma fibrinolytic activity and increase plasminogen activator inhibitor type 1 in the rat. Acta Diabetologica. 2001; 38(2):71-76. [PubMed: 11757804]

51. Weekers F, Giulietti AP, Michalaki M, et al. Metabolic, endocrine, and immune effects of stress hyperglycemia in a rabbit model of prolonged critical illness. Endocrinology. 2003; 144(12):5329_ 5338. [PubMed: 12960028]

52. Delamaire M, Maugendre D, Moreno M, et al. Impaired leucocyte functions in diabetic patients. Diabetic Medicine. 1997; 14(1):29-34. [PubMed: 9017350]

*53. Furnary AP, Wu Y, Bookin SO. Effect of hyperglycemia and continuous intravenous insulin infusions on outcomes of cardiac surgical procedures: the Portland Diabetic Project. Endocrine Practice. 2004; 10(Suppl. 2):21-33. [PubMed: 15251637]

54. Baker ST, Chiang CY, Zajac JD, et al. Outcomes for general medical inpatients with diabetes mellitus and new hyperglycaemia. The Medical Journal of Australia. 2008; 188(6):340-343. [PubMed: 18341457]

55. Donner TW, Flammer KM. Diabetes management in the hospital. Medical Clinics of North America. 2008; 92(2):407-425. [PubMed: 18298986]

56. Van den Berghe G, Wouters PJ, Bouillon R, et al. Outcome benefit of intensive insulin therapy in the critically ill: insulin dose versus glycemic control. Critical Care Medicine. 2003; 31(2):359366. [PubMed: 12576937]

57. Falciglia M, Freyberg RW, Almenoff PL, et al. Hyperglycemia-related mortality in critically ill patients varies with admission diagnosis. Critical Care Medicine. 2009; 37(12):3001-3009. [PubMed: 19661802]

*58. Krinsley JS. Blood glucose control in critically ill patients: the impact of diabetes. Critical Care Medicine. 2009; 37(1):382. author reply 382-3. [PubMed: 19112326]

59. Malmberg K, Ryden L, Hamsten A, et al. Effects of insulin treatment on cause-specific one-year mortality and morbidity in diabetic patients with acute myocardial infarction. DIGAMI Study Group. Diabetes Insulin-Glucose in Acute Myocardial Infarction. European Heart Journal. 1996; 17(9):1337-1344. [PubMed: 8880018]

60. Van den Berghe G, Wilmer A, Hermans G, et al. Intensive insulin therapy in the medical ICU. The New England Journal of Medicine. 2006; 354(5):449-461. [PubMed: 16452557]

61. Finney SJ, Zekveld C, Elia A, et al. Glucose control and mortality in critically ill patients. Jama. 2003; 290(15):2041-2047. [PubMed: 14559958]

62. Furnary AP, Gao G, Grunkemeier GL, et al. Continuous insulin infusion reduces mortality in patients with diabetes undergoing coronary artery bypass grafting. The Journal of Thoracic and Cardiovascular Surgery. 2003; 125(5):1007-1021. [PubMed: 12771873]

63. Furnary AP, Wu Y. Eliminating the diabetic disadvantage: the Portland diabetic project. Seminars in Thoracic Cardiovascular Surgery. 2006; 18(4):302-308. [PubMed: 17395026]

64. Furnary AP, Wu Y. Clinical effects of hyperglycemia in the cardiac surgery population: the Portland Diabetic Project. Endocrine Practice. 2006; 12(Suppl. 3):22-26. [PubMed: 16905513]

65. Brunkhorst FM, Engel C, Bloos F, et al. Intensive insulin therapy and pentastarch resuscitation in severe sepsis. The New England Journal of Medicine. 2008; 358(2):125-139. [PubMed: $18184958]$ 
*66. De La Rosa Gdel C, Donado JH, Restrepo AH, et al. Strict glycaemic control in patients hospitalised in a mixed medical and surgical intensive care unit: a randomised clinical trial. Critical Care. 2008; 12(5):R120. [PubMed: 18799004]

*67. Finfer S, Chittock DR, Su SY, et al. Intensive versus conventional glucose control in critically ill patients. N Engl J Med. 2009; 360(13):1283-1297. [PubMed: 19318384]

68. Preiser JC, Brunkhorst F. Tight glucose control and hypoglycemia. Critical Care Medicine. 2008; 36(4):1391. author reply 1391-2. [PubMed: 18379293]

*69. Griesdale DE, de Souza RJ, van Dam RM, et al. Intensive insulin therapy and mortality among critically ill patients: a meta-analysis including NICE-SUGAR study data. Canadian Medical Association Journal. 2009; 180(8):821-827. [PubMed: 19318387]

70. Preiser JC, Devos P, Ruiz-Santana S, et al. A prospective randomised multi-centre controlled trial on tight glucose control by intensive insulin therapy in adult intensive care units: the Glucontrol study. Intensive Care Medicine. 2009; 35(10):1738-1748. [PubMed: 19636533]

71. Zoungas S, Patel A, Chalmers J, et al. Severe hypoglycemia and risks of vascular events and death. The New England Journal of Medicine. 2010; 363(15):1410-1418. [PubMed: 20925543]

72. Preiser JC, Devos P, Ruiz-Santana S, et al. A prospective randomised multi-centre controlled trial on tight glucose control by intensive insulin therapy in adult intensive care units: the Glucontrol study. Intensive Care Medicine. 2009

*73. Kosiborod M, Inzucchi SE, Goyal A, et al. Relationship between spontaneous and iatrogenic hypoglycemia and mortality in patients hospitalized with acute myocardial infarction. Jama. 2009; 301(15):1556-1564. [PubMed: 19366775]

74. Ichai C, Preiser JC. International recommendations for glucose control in adult non diabetic critically ill patients. Critical Care. 2010; 14(5):R166. [PubMed: 20840773]

75. Kavanagh BP, McCowen KC. Clinical practice. Glycemic control in the ICU. The New England Journal of Medicine. 2010; 363(26):2540-2546. [PubMed: 21175316]

76. Corstjens AM, Ligtenberg JJ, van der Horst IC, et al. Accuracy and feasibility of point-of-care and continuous blood glucose analysis in critically ill ICU patients. Critical Care. 2006; 10(5):R135. [PubMed: 16981981]

77. Holzinger U, Warszawska J, Kitzberger R, et al. Impact of shock requiring norepinephrine on the accuracy and reliability of subcutaneous continuous glucose monitoring. Intensive Care Medicine. 2009; 35(8):1383-1389. [PubMed: 19350213]

78. Holzinger U, Warszawska J, Kitzberger R, et al. Real-time continuous glucose monitoring in critically ill patients: a prospective randomized trial. Diabetes Care. 2010; 33(3):467-472. [PubMed: 20007948]

*79. Moghissi ES, Korytkowski MT, DiNardo M, et al. American Association of Clinical Endocrinologists and American Diabetes Association consensus statement on inpatient glycemic control. Endocrine Practice. 2009; 15(4):353-369. [PubMed: 19454396]

80. Rodbard HW, Blonde L, Braithwaite SS, et al. American Association of Clinical Endocrinologists medical guidelines for clinical practice for the management of diabetes mellitus. Endocrine Practice. 2007; 13(Suppl. 1):1-68. [PubMed: 17613449]

81. O'Malley CW, Emanuele M, Halasyamani L, et al. Bridge over troubled waters: safe and effective transitions of the inpatient with hyperglycemia. Journal of Hospital Medicine. 2008; 3(5 Suppl): 55-65. [PubMed: 18951384]

82. Donaldson S, Villanuueva G, Rondinelli L, et al. Rush University guidelines and protocols for the management of hyperglycemia in hospitalized patients: elimination of the sliding scale and improvement of glycemic control throughout the hospital. The Diabetes Educator. 2006; 32(6): 954-962. [PubMed: 17102162]

83. Schmeltz LR, DeSantis AJ, Schmidt K, et al. Conversion of intravenous insulin infusions to subcutaneously administered insulin glargine in patients with hyperglycemia. Endocrine Practice. 2006; 12(6):641-650. [PubMed: 17229660]

84. Grainger A, Eiden K, Kemper J, et al. A pilot study to evaluate the effectiveness of glargine and multiple injections of lispro in patients with type 2 diabetes receiving tube feedings in a cardiovascular intensive care unit. Nutrition in Clinical Practice. 2007; 22(5):545-552. [PubMed: 17906278] 
85. Donihi AC, Raval D, Saul M, et al. Prevalence and predictors of corticosteroid-related hyperglycemia in hospitalized patients. Endocrine Practice. 2006; 12(4):358-362. [PubMed: 16901792]

86. Umpierrez GE, Hor T, Smiley D, et al. Comparison of inpatient insulin regimens with detemir plus aspart versus neutral protamine hagedorn plus regular in medical patients with type 2 diabetes. The Journal of Clinical Endocrinology and Metabolism. 2009; 94(2):564-569. [PubMed: 19017758]

87. Umpierrez GE, Smiley D, Jacobs S, et al. Randomized study of basal bolus insulin therapy in the inpatient management of patients with type 2 diabetes undergoing general surgery (RABBIT 2 surgery). Diabetes Care. 2011

88. Clement S, Braithwaite SS, Magee MF, et al. Management of diabetes and hyperglycemia in hospitals. Diabetes Care. 2004; 27(2):553-591. [PubMed: 14747243]

89. Lauster CD, Gibson JM, DiNella JV, et al. Implementation of standardized instructions for insulin at hospital discharge. Journal of Hospital Medicine. 2009; 4(8):E41-E42. [PubMed: 19827044]

90. Cook CB, KM Seifert, Hull BP, et al. Inpatient to outpatient transfer of diabetes care: planing for an effective hospital discharge. Endocrine Practice. 2009; 15(3):263-269. [PubMed: 19364697]

91. Maynard G, Wesorick DH, O'Malley C, et al. Subcutaneous insulin order sets and protocols: effective design and implementation strategies. Journal of Hospital Medicine. 2008; 3(5 Suppl): 29-41. [PubMed: 18951386] 


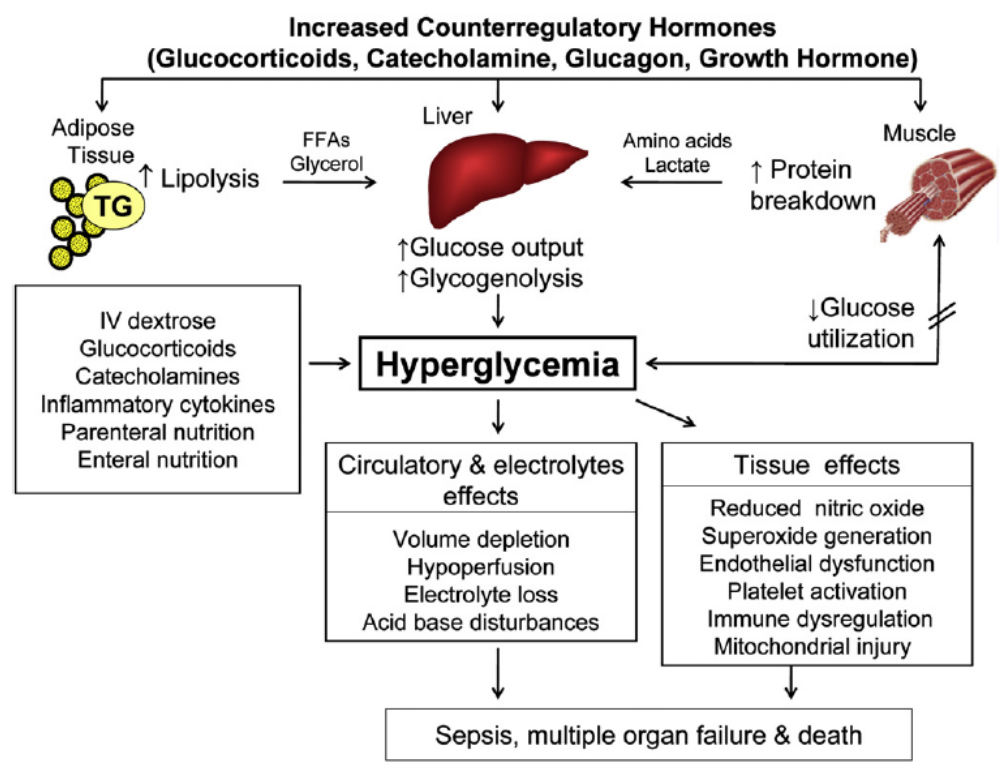

Fig. 1.

Pathogenesis of stress hyperglycemia Stress hyperglycemia results from increased hepatic glucose production and impaired glucose utilization in peripheral tissues. Excess counterregulatory hormones (glucagon, cortisol, catecholamines, and growth hormone) increases lipolysis and protein breakdown (proteolysis), and impaired glucose utilization by peripheral tissues. Hyperglycemia causes osmotic diuresis that leads to hypovolemia decreased glomerular filtration rate and worsening hyperglycemia. At the cellular level increased blood glucose levels results in mitochondrial injury by generating reaction oxygen species and endothelial dysfunction by inhibiting nitric oxide production. Hyperglycemia increases levels of pro-inflammatory cytokine such as TNF-a, and IL-6 leading to immune system dysfunction, also increases plasminogen activator inhibitor-1 and fibrinogen causing platelet aggregation and hypercoagulable state. These changes can eventually lead to increased risk of infection, impaired wound healing, multiple organ failure, prolonged hospital stay and death. 


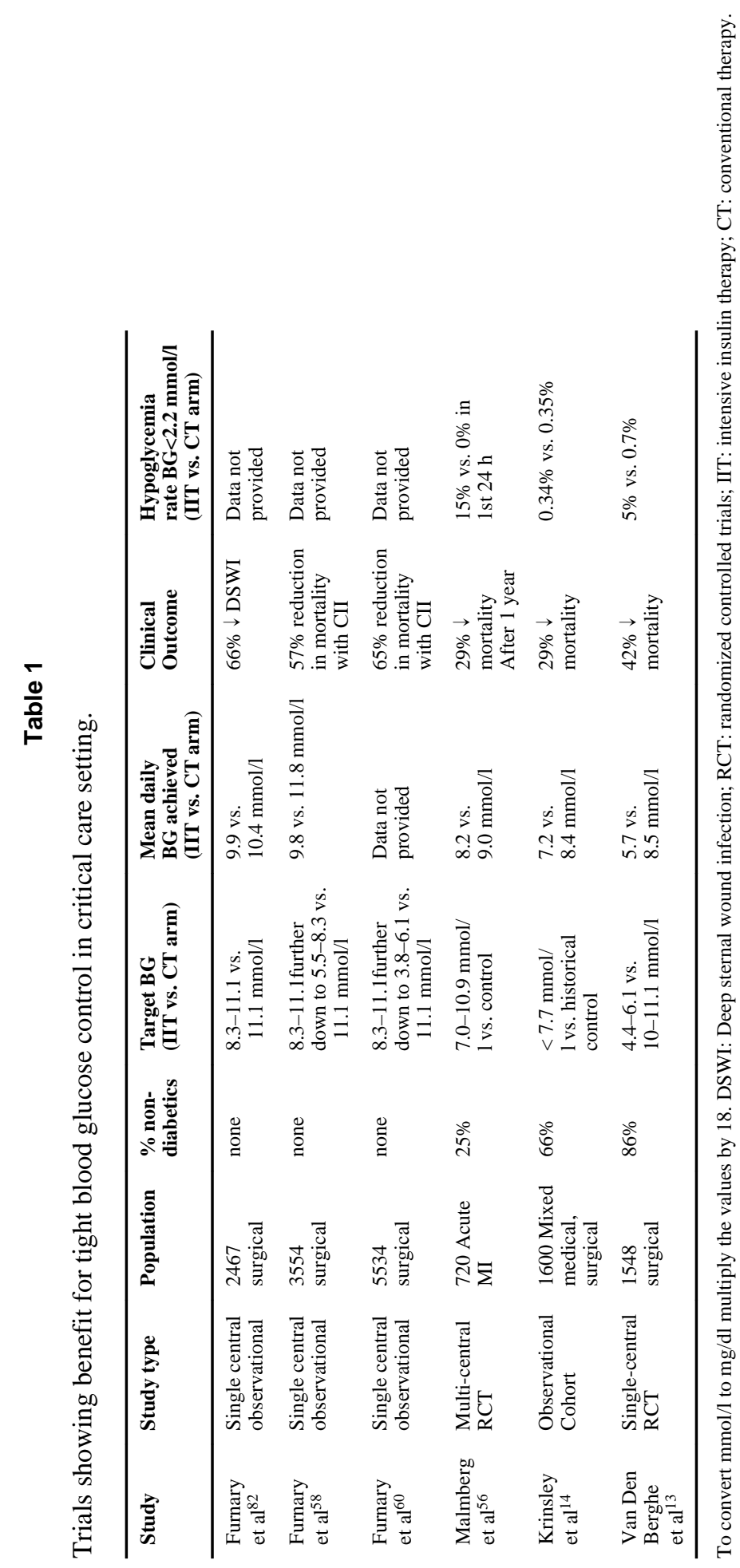

Best Pract Res Clin Endocrinol Metab. Author manuscript; available in PMC 2013 July 22. 


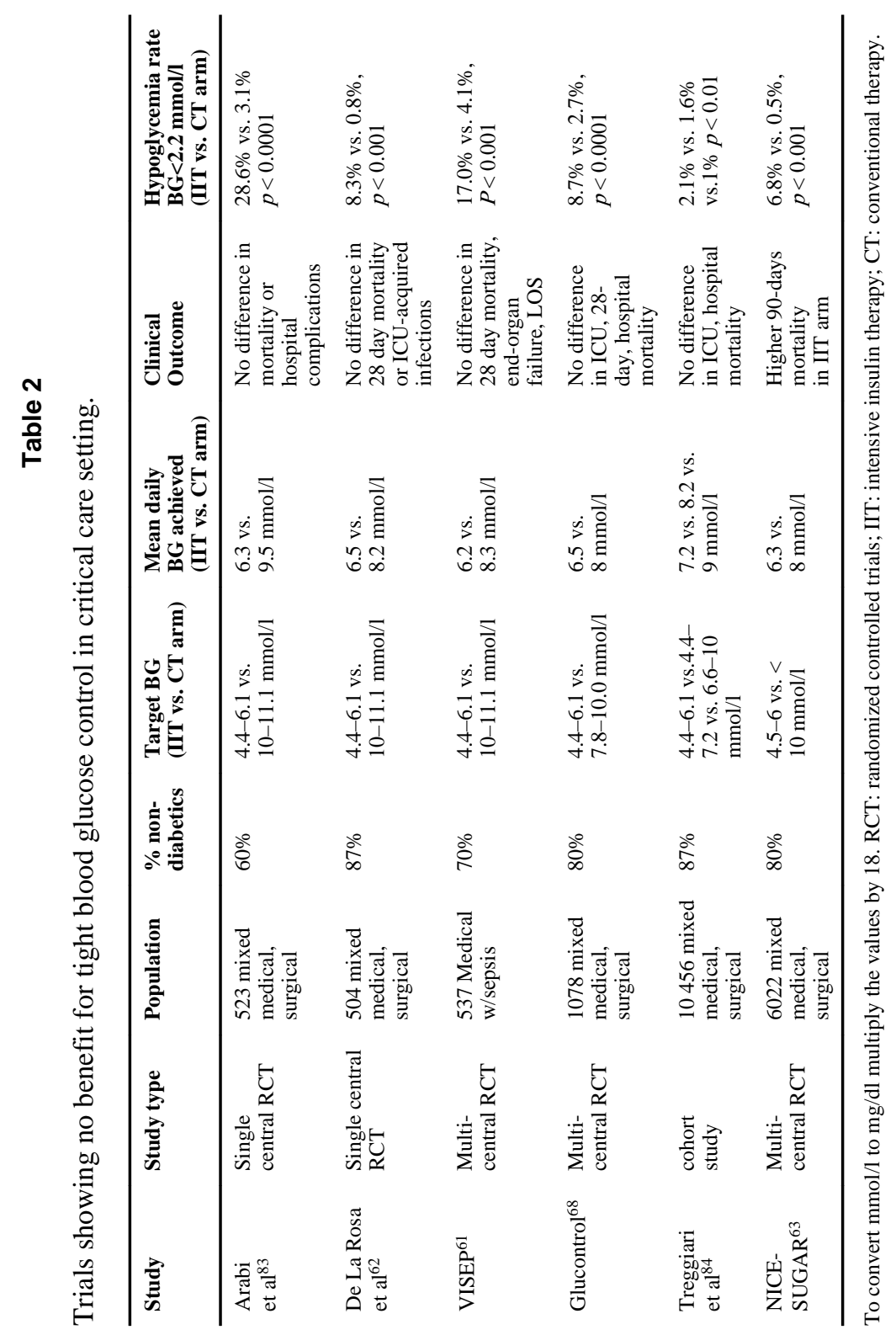

Best Pract Res Clin Endocrinol Metab. Author manuscript; available in PMC 2013 July 22. 